\title{
PERCEPÇÃO DE PROFESSORES SOBRE ALUNOS SUPERDOTADOS
}

\section{TEACHERS' PERCEPTION ABOUT GIFTED STUDENTS}

\author{
Renata Rodrigues MAIA-PINTO ${ }^{1}$ \\ Denise de Souza FLEITH ${ }^{2}$
}

\begin{abstract}
RESUMO
Esse estudo investigou a percepção do professor de ensino fundamental e de educação infantil sobre o aluno superdotado. Questionários foram aplicados em um grupo de 41 professores de escolas particulares e públicas de Brasília. Uma abordagem qualitativa foi usada nesse estudo. Procedeu-se a uma análise de conteúdo dos dados obtidos. Os resultados sugeriram que tanto os professores de escolas públicas quanto os de escolas particulares consideram importante o papel da escola na educação do aluno superdotado. Entretanto, não adotavam medidas ou instrumentos para identificação desses alunos, nem os atendiam de forma diferenciada. Os professores relataram nunca terem trabalhado com alunos superdotados. A maioria dos professores possuía um conhecimento superficial do conceito de superdotação, do processo de identificação do aluno superdotado e não contava com uma orientação específica sobre práticas educacionais compatíveis com as necessidades desses alunos superdotados.
\end{abstract}

Palavras-chave: superdotação, percepção de professores, ensino especial.

\begin{abstract}
The purpose of this study was to investigate elementary school teachers' perception about gifted students. Questionnaires were administered to 41 teachers from private and public schools in Brasilia. A qualitative approach was used in this study and the data were analyzed through content analysis. The findings suggest that both private and public schools teachers believe that the involvement of the school in the gifted student

(2) Ph.D. pela University of Connecticut - Professora do Instittuto de Psicologia da Universidade de Brasília.
\end{abstract}

(1) Mestranda em Psicologia na Universidade de Brasília - Bolsista da CAPES.

Correspondência: SQS 405 bloco K ap. 102 - Brasília - DF

70239-110 - E-mail: renatam@zaz.com.br 
educational process is important. On the other hand, neither public nor private schools adopted any kind of student identification system or had a special program for those students. The teachers reported that they have never had a gifted student in their classrooms. It was observed that most teachers have a superficial information about the concept of giftedness, identification processes, and educational strategies that could attend the needs of gifted students.

Key words: giftedness, teachers' perception, special education.

\section{INTODUÇÃO}

Vários autores (Alencar, 1986; Amabile, 1989; Csikszentmihalyi, 1996; Starko, 1995; Virgolim,1998) têm ressaltado a importância da figura do professor em sala de aula e a necessidade de planejamentos e estratégias educacionais adequados ao desenvolvimento de competências. É indiscutível que o professor pode criar um clima, em sala de aula, que favoreça o desenvolvimento de habilidades, da imaginação, da criatividade e do talento. Observa-se, no entanto, que as práticas de sala de aula ainda estão muito calcadas em modelos tradicionais que enfatizam sobretudo a aquisição passiva de conteúdos. Esse enfoque tradicional advém de alguns fatores como uma política educacional que não valoriza o talento ou a criatividade, deficiência na formação dos professores que não são preparados para reconhecer e trabalhar esses aspectos e uma prática educacional muito distante da teoria.

Surge no país uma corrida à modernização nas empresas e, conseqüentemente, uma demanda por indivíduos talentosos e criativos. Considerando-se essa tendência, surgem questões relativas ao papel da escola na preparação e desenvolvimento desses talentos.

Alencar (1986), quando fala sobre o crescente interesse, nas últimas décadas, com relação ao superdotado, ressalta:

Esse interesse é possivelmente fruto da consciência de que o futuro de qualquer nação depende da qualidade $e$ competência de seus profissionais, da extensão em que a excelência for cultivada e do grau em que condições favoráveis ao desenvolvimento do talento, sobretudo do talento intelectual, estiverem presentes desde os primeiros anos da infância. (p. xi)

Segundo as Leis de Diretrizes e Bases do Conselho Nacional de Educação Especial, (Ministério da Educação, 1995) adotadas por alguns programas brasileiros, são consideradas crianças superdotadas e talentosas as que apresentam notável desempenho e/ou elevada potencialidade em qualquer dos aspectos, isolados ou combinados: capacidade intelectual superior; aptidão acadêmica específica; pensamento criador ou produtivo; capacidade de liderança; talento especial para artes visuais, artes dramáticas e música e capacidade psicomotora. Entretanto, segundo Renzulli (1986), essa concepção, apesar de abranger diversas áreas, não leva em consideração fatores não-intelectuais além de não incluir categorias paralelas, uma vez que aptidões e altos desempenhos podem aparecer em mais de uma área, como criatividade e liderança.

Neste sentido, Renzulli (1986) propõe uma definição de superdotação baseada na concepção dos três-anéis, que sugere o entrelaçamento de três fatores: habilidade acima da média, envolvimento com a tarefa e criatividade. Cada um desses fatores exerce um papel importante na identificação de comportamentos superdotados. 
Habilidade acima da média envolve habilidades gerais, que consistem na capacidade de processar informações, de integrar experiências que resultem em respostas apropriadas e adaptadas a novas situações, bem como habilidades específicas, que consistem na capacidade de adquirir conhecimento, prática e habilidades para atuar em uma ou mais atividades de uma área específica.

Envolvimento com a tarefa, refere-se à motivação, uma energia canalizada para uma tarefa em particular ou uma área específica, assim como perseverança, persistência, dedicação e autoconfiança.

O terceiro fator, criatividade, envolve fluência, flexibilidade e originalidade de pensamento, abertura a novas experiências, curiosidade, sensibilidade e coragem para correr riscos. É importante ressaltar que os três fatores não precisam estar interagindo ao mesmo tempo e nem na mesma intensidade, mas é necessário que interajam em algum grau para que possam resultar em um alto nível de produtividade.

A partir da concepção dos três fatores, Renzulli propõe uma sistemática de identificação de alunos superdotados, denominada Grupos de Talentos. Segundo Fleith (s.d.), uma das vantagens desse sistema de identificação é que ele não predetermina quem é o aluno superdotado, evitando rótulos e possibilita a inclusão contínua de alunos em programas que oferecem oportunidades de experiências de aprendizagem avançadas e criativas.

O papel do professor e da escola na identificação do aluno superdotado ou talentoso é de fundamental importância. É o professor que, através do contato diário com o aluno, pode perceber sinais de um potencial superior e, assim, fazer uma primeira identificação desse indivíduo. Daí para frente, as relações estabelecidas com esse aluno serão de fundamental importância para o seu desenvolvimento. Nesse momento, a política de atendimento adotada pela escola poderá incentivar ou podar esse desenvolvimento. Programas de enriquecimento, estratégias de ensino e clima de sala de aula serão marcos na educação do aluno superdotado.

Existem hoje, em diversas escolas brasileiras, vários programas para atendimento a alunos especiais. Porém, a grande maioria está direcionada para crianças infradotadas ou para crianças deficientes. Segundo Fleith (s.d.), a idéia de que o aluno superdotado tem recursos suficientes para desenvolver habilidades e produzir conhecimento é um mito que se reflete no desenvolvimento de práticas educativas direcionadas a essa clientela. É necessário que se desenvolvam estratégias educacionais que atendam as necessidades dos alunos superdotados e talentosos. Neste sentido, algumas práticas educacionais têm sido usualmente indicadas para o trabalho com o aluno superdotado (Alencar, 1986; Fleith, s.d.; Renzulli, 1986). Dentre elas, podem ser ressaltadas 0 enriquecimento curricular, a aceleração, a compactação do currículo e a diferenciação curricular.

Segundo Virgolim (1998), para que o talento criativo seja corretamente identificado, estimulado e potencializado ao máximo em nossos jovens, é necessário atentarmos para o papel fundamental da escola neste processo.

Csikszentmihalyi (1996) afirma que muitas pessoas são introduzidas nas áreas de interesse por professores e que são eles que, na maioria das vezes, estimulam a curiosidade, reconhecem as habilidades dos alunos e começam a cultivá-las nas disciplinas. Csikszentmihalyi ressalta, ainda, a importância de se promover um ambiente harmonioso e significativo no espaço e no tempo para ajudar as crianças a se tornarem criativas.

Relatos de pesquisas mostram que professores despreparados podem excluir alunos de programas de superdotação ou rejeitá-los em sala de aula. Neste sentido, 
Shaughnessy, Stockard, Stanley e Siegel (1996), a partir de relatos de professores, observaram que alunos superdotados podem ser rejeitados por seus professores que não têm uma preparação pedagógica para desafiar essas crianças e propor modificações necessárias no currículo. Eles sugerem, ainda, que os professores devem consultar outros profissionais de forma colaborativa e buscar conhecimentos adicionais para o seu trabalho de magistério com crianças superdotadas. Webstby (1997), examinando a percepção de professores sobre o aluno criativo, concluiu que o conceito de criatividade apresentado pelos professores difere daquele de criatividade sugerido por especialistas e pesquisadores. Segundo Webstby, esse fato levou os pesquisadores a concluírem que os professores têm excluído ou rejeitado alunos criativos, uma vez que desconhecem as características pessoais associadas à criatividade e que não há um processo sistematizado de identificação dessa clientela. Da mesma forma, Chan e Chan (1999) argumentam que crianças com comportamento criativo podem se tornar indesejáveis em sala de aula, dependendo de como o professor julga esse comportamento.

Campbell e Verna (1998), ao estudarem a percepção de professores sobre o dia-a-dia de um programa de enriquecimento, concluíram que os professores formam uma definição própria do aluno superdotado, baseada no seu comportamento, atitudes e desempenho escolar. Perceberam que a maioria dos professores tinha um treinamento inicial muito limitado para trabalhar com os alunos superdotados e que, portanto, precisava de mais treinamento, informações e apoio. Também, Galloway e Porath (1997) observaram que a concepção inadequada do professor sobre superdotação pode resultar em uma expectativa inapropriada sobre o aluno superdotado, colocando esse aluno em risco.

Porath (1997), quando investigou como professores avaliavam a afetividade e a motivação de seus alunos, verificou que a maneira como o professor percebe diferenças individuais na aprendizagem do superdotado, sua motivação, suas habilidades e suas relações sociais, pode trazer implicações nos planos educacionais que geralmente são fechados. Outras pesquisas concordam que tanto professores regentes quanto professores que estão iniciando sua participação em programas de superdotação devem receber treinamento especialmente em relação ao conceito e à identificação do aluno superdotado (Ferbezer, 1998; Tirri, Tallent-Runnels \& Adams, 1998; Galloway \& Porath, 1997; Fraiser, Hunsaker, Lee, Finley, Frank, Garcia \& Martin, 1995; Hunsaker,1994; Siegel \& Moore, 1994).

A dificuldade, por parte das escolas e dos professores, em reconhecer e valorizar talentos foi o que motivou este trabalho que buscou indicações de como o professor percebe o aluno superdotado e como tem sido, na prática, a identificação e o atendimento a esse aluno. Neste sentido, o objetivo deste estudo foi investigar a percepção do professor do ensino fundamental e da educação infantil de Brasília sobre o aluno superdotado e a importância atribuída por ele ao papel da escola no atendimento das necessidades do aluno superdotado.

As seguintes questões de pesquisa foram examinadas:

1. Qual é a concepção do professor sobre superdotação?

2. Como o aluno superdotado pode ser identificado por seu professor?

3. Segundo o professor, que estratégias educacionais podem ser empregadas no trabalho com o aluno superdotado?

4. Qual é a percepção do professor sobre o papel da escola na educação do superdotado? 


\section{MÉTODO}

\section{Participantes}

Participaram do estudo 41 professores, sendo 20 professores de três escolas particulares e 21 professores de três escolas públicas de Brasília. Todos os sujeitos eram do sexo feminino e tinham em média 30 anos de idade. A maioria tinha entre 6 e 15 anos de experiência no magistério, nível superior e/ou pós-graduação e nunca havia participado de treinamentos na área de superdotação (apenas duas professoras de escola particular e quatro professoras de escola pública afirmaram ter participado de palestras que abordaram o tema).

A maior parte dos professores das escolas particulares trabalhava no estabelecimento há mais de cinco anos e a maioria dos professores das escolas públicas há menos de um ano. Das escolas particulares, duas professoras lecionavam na educação infantil ( $1^{\circ}$ e $2^{\circ}$ períodos), quatro professores lecionavam na educação infantil ( $3^{\circ}$ período alfabetização), oito professores lecionavam nas $1^{\mathrm{a}}$ e $2^{\mathrm{a}}$ séries do ensino fundamental, e seis professores lecionavam nas $3^{\mathrm{a}} \mathrm{e} 4^{\mathrm{a}}$ séries do ensino fundamental. Das escolas públicas, quatro professores lecionavam na educação infantil ( $1^{\circ}$ e $2^{\circ}$ períodos), um professor lecionava na educação infantil ( $3^{\circ}$ período alfabetização), seis professores lecionavam nas $1^{\mathrm{a}}$ e $2^{\mathrm{a}}$ séries do ensino fundamental, quatro professores lecionavam nas $3^{\mathrm{a}}$ e $4^{\mathrm{a}}$ séries do ensino fundamental, cinco professores lecionavam no ensino especial (trabalhando com crianças que apresentavam deficiência auditiva, deficiência visual ou déficit de aprendizagem), e uma professora estava ocupando cargo de direção temporariamente. A maior parte dos professores das escolas públicas afirmou ter em média 25 alunos em suas salas de aula. A maior parte dos professores das escolas particulares afirmou ter em média 20 alunos em sala de aula.

\section{Instrumentos}

Um questionário foi elaborado para a coleta de dados deste estudo. O questionário, com 14 questões, incluía os seguintes tópicos: conceito de superdotação, identificação do aluno superdotado, estratégias de ensino e influência da escola na educação do superdotado, concordância ou não sobre implantação de programas de atendimento ao aluno, tipos de medidas ou instrumentos utilizados pela escola na identificação do superdotado, existência ou não de programas de atendimento na escola, além de dados pessoais, tais como, sexo, idade, escolaridade, número de alunos por sala, tempo de formação e tempo de trabalho na escola.

Esse instrumento foi analisado por um especialista de pesquisa em psicologia e uma especialista na área de superdotação e criatividade.

\section{Procedimentos}

A seleção das escolas públicas foi feita por intermédio da Delegacia Regional de Ensino da Secretaria de Educação do Distrito Federal que, sorteou 3 escolas de uma lista de escolas da região sul do plano piloto de Brasília. Procurou-se localizar, também, nesse bairro, as escolas particulares. As escolas deveriam abranger a educação infantil e o ensino fundamental e os professores deveriam atuar nesses níveis. Foram feitas visitas a algumas escolas particulares da região sul e, as três primeiras que concordaram em participar, foram incluídas na pesquisa.

A participação dos professores era mediante a concordância dos mesmos. Como uma das escolas públicas selecionadas abrangia até a $4^{a}$ série do ensino fundamental, decidimos limitar a pesquisa a essa mesma faixa.

Em cada escola era feito um primeiro contato com a coordenação, no qual eram apresentados os objetivos do estudo. Em seguida, os professores que concordaram em 
participar da pesquisa eram reunidos em uma sala da escola, onde recebiam algumas orientações a respeito da pesquisa e do questionário, que era respondido individualmente. O pesquisador esclarecia que a participação na pesquisa era voluntária e reforçou o convite, constante na introdução do questionário, para um workshop sobre superdotação, ministrado por uma especialista na área. Ao final da aplicação do instrumento as participantes recebiam um prospecto contendo informações sobre superdotação e um convite para o workshop.

\section{Tratamento dos Dados}

Este foi um estudo descritivo no qual foi utilizado o survey como método de pesquisa. Uma abordagem qualitativa foi usada para a análise dos dados. A partir deste enfoque, os dados foram tratados através de uma análise de conteúdo. Unidades de significância (códigos) foram designadas para os dados coletados. Essas unidades foram agrupadas e categorias foram geradas. A análise se completou com a relação feita entre as categorias produzidas (Marshall \& Rossmann, 1995). Foi realizado, ainda, um levantamento da freqüência e do percentual das categorias geradas.

\section{Resultados}

Quatro questões de pesquisa foram investigadas nesse estudo. Os resultados obtidos serão descritos a seguir.

\section{Questão de Pesquisa 1: Definição de superdotação}

A respeito do conceito de superdotação, seis categorias de respostas emergiram: capacidade e/ou desempenho extraordinário em áreas específicas, facilidade de aprendizagem, desenvolvimento avançado, conhecimento acima da média, inadaptação e problemas de comportamento e capacidade intelectual superior (QI) (veja Tabela 1).

As categorias mais ressaltadas pelos professores de escolas públicas foram Capacidade e/ou Desempenho extraordinário em áreas específicas (48\%) e Conhecimento acima da média (19\%). Os professores de escola particular enfatizaram as categorias relacionadas à Capacidade e/ou Desempenho extraordinário em áreas específicas (32\%) e Facilidade de aprendizagem (32\%). Dois professores informaram que possuíam pouco conhecimento a respeito do termo superdotação. As categorias pouco

Tabela 1. Número e Percentual das Respostas sobre o Conceito de Superdotação Apresentadas pelos Professores $(\mathrm{N}=41)$.

\begin{tabular}{|lllll|}
\hline \multirow{2}{*}{ Categorias } & \multicolumn{4}{c|}{ Tipo de Escola } \\
\cline { 2 - 5 } & \multicolumn{2}{c}{ Particular } & \multicolumn{2}{c|}{ Pública } \\
\hline Capacidade ou desempenho acima da média & 7 & 32 & 10 & 48 \\
Facilidade de aprendizagem & 7 & 32 & 0 & 0 \\
Conhecimento acima da média & 1 & 5 & 4 & 19 \\
Desenvolvimento superior ao da faixa etária & 2 & 9 & 3 & 14 \\
Inadaptação e problemas de comportamento & 2 & 9 & 2 & 10 \\
Capacidade intelectual superior & 1 & 5 & 2 & 10 \\
\hline
\end{tabular}


mencionadas pelos professores de ambos os grupos foram Capacidade intelectual superior e Inadaptação e problemas de comportamento. As categorias são descritas a seguir.

- Capacidade e/ou desempenho extraordinário em áreas específicas: diz respeito a um desempenho maior em uma área, maior conhecimento em uma matéria, talento especial em uma área específica, desempenho superior nas áreas cognitiva e motora.

- Facilidade de aprendizagem: envolve a execução de tarefas que outras crianças da mesma idade não fazem, desempenho maior do que o esperado para a idade, crianças que se destacam do grupo, criança que vai além e que está sempre buscando, facilidade de adquirir conhecimento e assimilar conteúdo maior que a dos colegas.

- Conhecimento acima da média: envolve conhecimento maior que dos colegas, criança que se sobressai perante 0 conhecimento da turma ou criança que aprende com facilidade maior do que a turma.

- Inadaptação e problemas de comportamento: refere-se às crianças que não se adaptam à rotina de sala de aula, que tem características de hiperatividade e déficit de atenção.

- Capacidade intelectual superior: diz respeito à criança mais inteligente, ou com inteligência acima do normal.

\section{Questão de Pesquisa 2: Identificação do aluno superdotado}

Investigou-se junto aos professores como eles identificariam um aluno superdotado em sua sala de aula. As respostas para essa pergunta foram distribuídas em duas categorias: Características do aluno e Estratégia (veja Tabela 2).

Tabela 2. Número e Percentual das Respostas Apresentadas pelos Professores sobre a Identificação do Aluno Superdotado $(\mathrm{N}=41)$.

\begin{tabular}{|c|c|c|c|c|}
\hline \multirow{3}{*}{ Categorias } & \multicolumn{4}{|c|}{ Tipo de Escola } \\
\hline & \multicolumn{2}{|c|}{ Particular } & \multicolumn{2}{|c|}{ Pública } \\
\hline & $\mathrm{n}$ & $\%$ & $\mathrm{n}$ & $\%$ \\
\hline \multicolumn{5}{|l|}{ Características do aluno } \\
\hline $\begin{array}{l}\text { Facilidade de aprender e/ou desempenho } \\
\text { avançado }\end{array}$ & 5 & 25 & 9 & 43 \\
\hline $\begin{array}{l}\text { Problemas de comportamento e emocionais } \\
\text { em função da aprendizagem acima da média }\end{array}$ & 9 & 45 & 3 & 14 \\
\hline Opinião diferenciada dos colegas & 1 & 5 & 2 & 10 \\
\hline Grande interesse & 1 & 5 & 1 & 5 \\
\hline \multicolumn{5}{|l|}{ Estratégia } \\
\hline Avalição de desempenho diário & 1 & 5 & 3 & 14 \\
\hline Orientação de especialista da área & 3 & 15 & 3 & 14 \\
\hline
\end{tabular}


Em relação a Características do aluno, foram relacionadas as sub-categorias de respostas descritas a seguir.

- Facilidade de aprendizagem e/ou desempenho avançado: aluno com perspectiva de aprendizado acima da média, criança que supera os objetivos propostos, criança que está sempre buscando algo além do ensinado, desempenho maior em uma tarefa, facilidade de interpretação, aprendizagem fácil, muita criatividade e curiosidade.

- Problemas de comportamento e emocionais: rapidez nas tarefas e conseqüente desinteresse, alto desenvolvimento cognitivo e inquietação, agilidade na aplicação dos conhecimentos e agitação ou apatia, altas habilidades podendo apresentar problemas emocionais, social e motor, falta de interesse pelo conteúdo e inquietação.

- Opinião diferenciada dos colegas: visão ampla e opinião que não bate com das outras crianças, interesse além da matéria trabalhada, criança diferente dos outros em vários aspectos.

- Grande Interesse: criança que apresenta interesse extremamente acima do normal em uma área.

Em relação às respostas relacionadas à categoria Estratégia, duas subcategorias emergiram. Ambas são descritas a seguir.
- Avaliação de desempenho diário: observação das reações e desempenho do dia-a-dia, observação dos aspectos sociais e disciplinares, desempenho diário por meio das atividades propostas, observação do comportamento diário.

- Orientação de especialistas da área: buscar apoio psicopedagógico, solicitar ajuda de um profissional para identificar o aluno superdotado.

As respostas mais freqüentes apresentadas por professores da escola pública foram facilidade de aprender e/ou desempenho avançado (43\%) e as mais freqüentes apresentadas por professores da escola privada foram problemas de comportamento e emocionais (45\%)

\section{Questão de Pesquisa 3: Estratégias educacionais direcionadas para o aluno superdotado}

As respostas obtidas com relação à identificação das estratégias educacionais que estariam sendo utilizadas em sala de aula pelos professores, para atender às necessidades dos alunos superdotados, foram categorizadas como: Estratégias e atividades de ensino, Estimulação do potencial e ausência de alunos com desempenho superior (veja Tabela 3). Dois professores da escola pública não responderam essa questão.

Tabela 3. Número e Percentual das Respostas Apresentadas pelos Professores sobre Estratégias Educacionais Voltadas para o Aluno com Desempenho Superior $(\mathrm{N}=39)$.

\begin{tabular}{|lcccc|}
\hline & \multicolumn{4}{c|}{ Tipo de Escola } \\
\cline { 2 - 5 } Categorias & \multicolumn{2}{c|}{ Particular } & \multicolumn{2}{c|}{ Pública } \\
\hline Estratégias e atividades de ensino & $\mathrm{n}$ & $\%$ & $\mathrm{n}$ & $\%$ \\
Estimulação do potencial & 13 & 65 & 10 & 53 \\
Ausência de alunos com desempenho superior & 5 & 25 & 3 & 16 \\
\hline
\end{tabular}


As respostas obtidas para cada uma dessas categorias são apresentadas a seguir.

- Estratégias e atividades de ensino: propor atividades diversificadas, despertar o interesse, trabalho diferenciado, trabalhar separadamente com uma equipe de especialistas, propor atividades com maior grau de dificuldade, localizar as habilidades desse aluno em benefício da turma e levá-lo a compreender as limitações da turma, deixar esse aluno auxiliando os colegas, desenvolver atividades paralelas de interesse, colocar a criança para ajudar o professor, procurar nivelar a turma, integrar o aluno ao grupo e propor desafios. Esta categoria foi a mais freqüentemente mencionada por professores do ensino público e privado.

- Estimulação do potencial: possibilitar descobertas de acordo com os anseios do aluno, atender às necessidades do aluno, promover ajuda psicológica, reforçar o conteúdo de domínio e introduzir novos, oferecer à criança boas condições de desempenho e propostas inovadoras que estimulem o potencial do aluno.

- Ausência de alunos com desempenho superior: o professor não tem possibilidades de identificar alunos superdotados por causa do grande número de alunos em sala de aula, não possui aluno com desempenho superior, nunca teve esse tipo de aluno, só teve experiência com alunos que apresentam déficit cognitivo. Esta categoria foi ressaltada por seis professores de escola pública e dois de escola particular.

As respostas mais freqüentes apresentadas tanto por professores da escola pública quanto da particular diziam respeito à Estratégias e atividades de ensino (53\% e $65 \%$ respectivamente). Interessante observar que $32 \%$ dos professores da escola pública e $10 \%$ dos professores da escola particular informaram nunca terem tido um aluno superdotado em sala de aula.

Questão de Pesquisa 4: Papel da escola no desenvolvimento do aluno superdotado

Com relação ao papel da escola na educação do aluno superdotado, três professoras de escola particular e três de escola disseram não acreditar na influência da escola na educação desse aluno, uma professora de escola pública e uma de escola particular afirmaram acreditar na influência da escola, porém, não apresentaram sugestões. As respostas apresentadas pelos outros professores foram agrupadas em três categorias: Preparação da escola e do professor, Práticas educacionais e Clima de sala de aula.

Tabela 4. Número e Percentual das Respostas Apresentadas pleos Professores acerca da Influência da Escola na Educação do Aluno Superdotado ( $N=37)$.

\begin{tabular}{|lcccc|}
\hline & \multicolumn{4}{c|}{ Tipo de Escola } \\
\cline { 2 - 5 } Categorias & \multicolumn{2}{c|}{ Particular } & \multicolumn{3}{c|}{ Pública } \\
\hline Preparação do professor e da escola & 10 & 50 & 11 & 65 \\
Práticas educacionais & 6 & 30 & 4 & 24 \\
Clima de sala de aula & 4 & 20 & 2 & 12 \\
\hline
\end{tabular}


Esses professores apresentaram várias respostas acerca da influência da escola na educação do aluno superdotado, as freqüências mencionadas na Tabela 4 dizem respeito ao número de respostas e não ao número de respondentes.

As respostas mais comuns a cada categoria são descritas a seguir.

- Preparação da escola e do professor: trabalho integrado com a família, apoio e suporte emocional, capacitando o professor, a escola pouco preparada pode prejudicar o aluno, falta de estrutura da escola para atender o aluno superdotado.

- Práticas educacionais: desenvolver habilidades e aptidões, ajudar na organização de idéia, oferecer ao aluno oportunidade de resolução de situações problemas, desenvolver atividades que atendam às necessidades dos alunos, e oferecer mais recursos materiais.

- Clima de sala de aula: estimular o convívio com outras crianças, ressaltar qualidades positivas, dar mais atenção ao aluno, estimular o potencial, e valorizar as idéias dos alunos.

As respostas mais freqüentes emitidas por professores de escolas públicas e privadas estavam relacionadas à Percepção do professor (65\% e 50\% respectivamente).

\section{DISCUSSÃO}

Não foram observadas diferenças marcantes entre professores de escola pública e professores de escola particular com relação à percepção do professor sobre o aluno superdotado. A tendência foi enfatizar o aspecto cognitivo do potencial do aluno, sem considerar o aspecto afetivo ou a criatividade.

Com relação ao conceito de superdotação fornecido pelos professores, observamos que os mesmos têm uma idéia superficial ou fracionada a respeito do conceito de superdotação. As respostas apresentadas pelos professores foram separadas em diferentes categorias (capacidade ou desempenho acima da média, facilidade de aprender, conhecimento acima da média, desenvolvimento superior ao da faixa etária, inadaptação e problemas de comportamento, capacidade intelectual superior), que juntas, com exceção de inadaptação e problemas de comportamento, poderiam se aproximar muito de uma definição adequada de superdotação mas que, vistas por partes, podem ser excludentes. Grande parte $(48 \%)$ dos professores das escolas públicas e dos professores das escolas particulares (32\%) relacionou o aluno superdotado àqueles que possuem capacidade ou desempenho acima da média. Esse conceito pode ser facilmente englobado tanto na definição apresentada por Renzulli (1986), quanto na apresentada por Alencar (1986), e constante das Diretrizes Gerais para o Atendimento Educacional aos Alunos Portadores de Altas Habilidades/ Superdotação e Talentos (Ministério da Educação, 1995) e nos Parâmetros Curriculares Nacionais (Ministério da Educação, 1999). Porém, os professores não esclareceram como seria este desempenho; alguns relacionaram a um grande conhecimento e outros a um desempenho superior. Dessa forma, esse conceito ficou perdido num aglomerado de definições.

As outras categorias de respostas apresentadas pelos professores, também, podem ser englobadas na definição de superdotação que hora nos baseamos, mas novamente, não de maneira isolada. Senão vejamos, desenvolvimento superior ao da faixa etária foi relacionado a crianças que se sobressaem às demais do grupo ou que têm facilidade em adquirir conhecimento. É fato que uma criança com essas características poderia ser incluída em um programa de enriquecimento, mas a definição de superdotação não se limita apenas a esse 
conceito. Crianças com outras características podem ser excluídas de programas de enriquecimento se a definição de superdotação for vista por apenas um parâmetro ou for baseada em mitos como relacionar superdotação a problemas emocionais ou a hiperatividade.

Alencar (1986) alerta para o fato de que o número de alunos superdotados que são indicados para programas especiais é muito pequeno, que a maior parte dos alunos superdotados tem permanecido nas salas de aulas regulares, com pouca oportunidade para desenvolverem seu potencial e que isso representa uma enorme perda para o país.

A falta de uma definição de superdotação por parte do professor limita as chances de uma criança ter o seu potencial desenvolvido ou de ser indicada para algum programa especial, uma vez que parte do professor, além da família, a primeira indicação ou o primeiro incentivo. O enfoque para se introduzir definitivamente um programa especial em uma escola, deveria estar centrado na preparação do professor, para que ele pudesse dar início a todo um processo. Alencar (1986) diz que é predominante um conceito limitado de superdotação e que ainda não foi assimilada a idéia de que a inteligência é composta de inúmeras dimensões. Esse fato foi confirmado por pesquisadores (Hunsaker, 1994; Galloway \& Porath, 1997; Westberg, Archambault \& Brown,1997; Campbell \& Verna, 1998; Ferbezer, 1998; Person, 1998; Lorna 1999; Fleith, 2000) que ressaltam a importância de um treinamento adequado para os professores e uma definição do conceito mais acertado de superdotação por parte das escolas.

O fato dos professores terem apresentado poucas estratégias ou alternativas de identificação do aluno superdotado está diretamente relacionado à falta de uma definição de superdotação. Fleith (s.d.) observa que alunos criativos e muito interessados podem ser facilmente excluídos de programas especiais conforme a sistemática de identificação.

As propostas predominantes de estratégias educacionais adotadas no trabalho com alunos com desempenho superior são estratégias que deveriam ser comuns a todos os alunos. Dentre estratégias e atividades de ensino, $65 \%$ dos professores de escola particular e $53 \%$ dos professores de escolas públicas, propuseram, entre outras: atividades diversificadas, trabalho diferenciado, trabalho com maior grau de dificuldade. Tais estratégias podem ser consideradas apropriadas para a maior parte das disciplinas e atividades escolares, inclusive para programas especiais. Observamos que $10 \%$ dos professores das escolas particulares e $32 \%$ dos professores das escolas públicas alegaram nunca terem trabalhado com alunos com desempenho superior. Parece que os anos de experiência no magistério e alto nível de escolaridade não foram suficientes para conscientizar o professor com relação a alunos com alto potencial em sua sala de aula.

A partir das respostas sobre o papel da escola na educação do superdotado e na importância da adoção de medidas educacionais, pudemos perceber que a maioria dos professores acredita que, se a escola estiver bem estruturada e os professores estiverem bem preparados, a influência da escola pode ser positiva para o desenvolvimento do aluno superdotado. Ao contrário, se a escola não estiver preparada, a influência pode ser negativa, podendo prejudicar esse aluno. Foi interessante notar que alguns professores, apesar da larga experiência no magistério e escolaridade em nível superior, afirmaram não acreditar na influência da escola na educação do aluno superdotado.

Nenhuma escola participante desse estudo adotava alguma definição de superdotação, medida ou instrumento de identificação de alunos superdotados. Não foi relatado nenhum tipo de programa de atendimento às necessidades dessa clientela. 
Nas escolas públicas encontramos cinco professoras que trabalhavam com turmas especiais, com alunos portadores de síndromes, deficiência mental, auditiva e visual. Notamos que, na rede pública de ensino, este tipo de aluno, vem recebendo devida atenção. Considerando que o ensino deveria abranger democraticamente a comunidade de alunos, poderíamos concluir que uma parte dessa comunidade está sendo negligenciada em seu direito, apesar de as diretrizes legais e os parâmetros curriculares vislumbrarem esse aluno. Como lembrou Alencar (1986), a valorização do talento é uma questão cultural e política. Davis e Rimm (1994) afirmam que a definição adotada por uma escola irá guiar o processo de seleção e determinar quem irá fazer parte de programas ou serviços especiais e, que uma definição e o conseqüente método de identificação podem discriminar uma população especial como os economicamente desfavorecidos e as minorias.

Os resultados desse estudo são similares aos das pesquisas conduzidas por Campbell e Verna (1998), Galloway e Porath (1997), Porath (1997), Siegel e Moore (1994) e Tirri, Tallent-Runnels e Adams (1998), e sugerem a necessidade das escolas de, inicialmente, conceituar o termo superdotação e caracterizar o aluno superdotado. Em seguida, ressaltam a importância de se delimitar medidas e instrumentos que professores e outros profissionais deverão usar para identificar o aluno superdotado e definir que programas de enriquecimento ou programas especiais serão adotados para o desenvolvimento desse aluno. Por fim, chamam a atenção para a necessidade de instruir, treinar, aperfeiçoar, orientar, enfim, dar suporte ao professor que vai ser a mola mestra desse processo.

\section{REFERÊNCIAS}

ALENCAR, E. M. L. (1986). Psicologia e educação do superdotado. São Paulo: E.P.U.
AMABILE, T. M. (1989). Growing up creativity. Nurturing a lifetime of creativity ( $2^{\text {nd }}$ ed.). Buffalo, NY: Creative Education Foundation.

CAMPBELL, J. R. \& Verna, M.A. (1998). Messages from the field: American teachers of the gifted talk back to the research community. Trabalho apresentado na Reunião Anual da Associação Americana de Pesquisa Educacional, San Diego, CA.

CHAN, D. W. \& Chan, L-K. (1999). Implicit theories of creativity: Teachers' perception of student characteristics in Hong Kong. Creativity Research Journal, 12, 185-195.

CSIKSZENTMIHALYI, M. (1996). Creativity, flow and the psychology of discovery and invention. New York: Harper Collins.

DAVIS, G. A. \& Rimm, S. B. (1994). Education of the gifted and talent ( $3^{\text {rd }}$ ed.). Boston: Allyn and Bacon.

FERBEZER, I. (1998). Validity and reability of teacher's judgement in identification and follow-up of gifted pupils. Gifted Education International, 12, 190-191.

FLEITH, D. S. (s.d.). Psicologia e educação do superdotado: definição, sistema de identificação e modelo de estimulação. Temas em Psicologia. (no prelo)

FLEITH, D. S. (2000). Teacher and student perceptions of creativity in the classroom environment. Roeper Review, 22, 148-153.

FRAISER, M. M., Hunsaker, S. L., Lee, J., Finley, V. S., Frank, E., Garcia, J. H. \& Martin, D. (1995). Educators' perception of barriers to the identification of gifted children from economically disvantaged and limited English proficient backgrounds. Storrs, CT: The National Research Center on Gifted and Talented.

GALLOWAY, B. \& Porath, M. (1997). Parent and teacher views of gifted children's social abilities. Roeper Review, 20, 118-121. 
HUNSAKER, S. L. (1994). Creativity as a characteristic of giftedness: Teachers see it, then they don't. Roeper Review, 17, 11-19.

LORNA, H. (1999). Teachers and the very able: Case studies of four scotiish. High Ability Studies, 10, 85-97.

MARSHALL, C. \& Rossmann, G. B. (1995). Designing qualitative research. Thousand Oaks, CA: Sage.

MINISTÉRIO DA EDUCAÇÃO. (1995). Diretrizes gerais para o atendimento educacional aos alunos portadores de altas habilidades/superdotação e talentos. Brasília, DF.

MINISTÉRIO DA EDUCAÇÃO. (1999). Parâmetros Curriculares Nacionais. Adaptações curriculares, estratégias para a educação de alunos com necessidades educacionais especiais. Brasília, DF.

PERSON, R. S. (1998). Paragons of virtude: Teachers' conceptual understanding of high ability in an egalitarian school system. High Ability Studies, 9, 181-197.

PORATH, M. (1997). Affective and motivational considerations in the assessment of gifted learners. Roeper Review, 19, 13-17.

RENZULLI, J. S. (1986). The three-ring conception of giftdness: A developmental model for creative productivity. Em R. J. Sternberg \& J. E. Davis (Eds.), Conception of giftedness (pp.53-92). New York: Cambridge University Press.
SHAUGHNESSY, M. J., Stockard, J. W., Stanley, N. V. \& Siegel, J. (1996). Gifted children's, teachers', and parents' perceptions of influential factors on gifted development. Gifted Education International, 11, 76-79.

SIEGEL, J. \& Moore, J. N. (1994). Regular education teachers' attitudes toward their identified gifted and special education students. Trabalho apresentado na Reunião Anual da Associação Americana de Educação Especial, Los Angeles, CA.

STARKO, A. J. (1995). Creativity in the classroom. White Plains, NY: Longman.

TIRRI, K. A., Tallent-Runnels, M.K. \& Adams, A.M. (1998). Cross-cultural study of teachers' attitudes toward gifted children programs. Trabalho apresentado na Reunião Anual da Associação Americana de Pesquisa Educacional, San Diego, CA.

VIRGOLIM, A. M. R. (1998). Uma proposta para o desenvolvimento da criatividade na escola, segundo o modelo Renzulli. Trabalho apresentado na XXVIII Reunião Anual de Psicologia, Ribeirão Preto, SP.

WEBSTBY, E. (1997). Do teachers value creativity? Gifted and Talented International, 12, 15-17.

WESTBERG, K. L., Archambault, F. X., Jr. \& Brown, S. W. (1997). A survey of classroom practices with third and fourth grade students in the United States. Gifted Education International, 12, 29-33. 